\title{
THE EFFECT OF KNEE JOINT ANGLE ON THE COACTIVATION OF PREPUBERTAL BOYS AND ADULT MALES
}

\author{
A. Hassani ${ }^{1}$, K. Gourgioti ${ }^{1}$, I. Paraschos ${ }^{1}$, E. Bassa ${ }^{1}$, D. Madic ${ }^{2}$, \\ C. Kotzamanidis ${ }^{1}$ \\ ${ }^{1}$ Department of Physical Education and Sports Sciences, \\ Aristotle University of Thessaloniki, Thessaloniki, Greece. \\ ${ }^{2}$ Faculty of Sport and Physical Education, University of Novisad, Serbia
}

\section{ABSTRACT}

The purpose of this study was to investigate the influence of knee joint angle on the maximum moment and activation level of the knee extensors and flexors for untrained pre-pubertal boys $(n=25$; age $9.8 \pm 1.1)$ and adult males $(n=25$; age 29.6 \pm 5.0$)$. Three maximal isometric voluntary knee extensions and flexions were performed at 3 different joint angles $(5 \%, 50 \%$ and $95 \%$ of the maximal range of knee flexion), while the integrated averaged electromyographic (iaEMG) activity of the vastus medialis (VM), vastus lateralis (VL), and long head of biceps femoris (BF) muscles were recorded. The results indicated that absolute and relative torque was higher in adults compared to children. Agonist activity was not affected in both groups by joint angles. Antagonist activity was higher in extreme angles in both groups and higher in children in all selected joint angle. These findings suggest that the joint angles caused a deficit in neuromuscular performance of children and it could be attributed to their higher antagonist activity.

Key words: muscle length, electromyography, co-activation, prepuberty, knee 


\section{INTRODUCTION}

The influence of muscle length on the torque output has been widely studied in vivo and in vitro in the past, confirming torque output alteration when muscle length changes [36]. This torque alteration is referred as length/tension relationship and it is usually expressed as torque/joint angle (TJA) relationship. The TJA history was mainly attributed to the so called "sliding filament theory" [36], according to which an overlap or reduction of actin-myosin cross bridges is observed at short or long lengths, respectively. Relevant studies have also shown that TJA is also affected by biomechanical $[34,36]$ and neuronal $[24,34]$ factors, as well.

Regarding the neuronal mechanisms conflicting results have been reported for the agonist and antagonist activity. Muscle agonist activity may be higher $[4,23,25,27,29,45]$ or unaltered [10, 33, 48] at the extreme angles. Similar controversy exists for the antagonist activity. It has been reported that coactivation is higher at the extreme angles $[12,23,25,27,30,43]$ or it remains constant $[4,8,16]$.

During the developmental period, skeletal muscles undergo structural, neural, metabolic and morphological changes [9]. Such changes result in a continuous strength increase due to the moment arm increase [34], and the muscle mass increment [38]. Regarding the neuronal factors prepubertal children exert their torque based on their feed forward system [42] and activate their motor unit in the same extend adults do, during plantar flexion $[17,18]$ and knee extension $[34,44]$. Children also demonstrated longer, electromechanically delay and lower rate of force development [3, 13]. The results are conflicting for the antagonist activity during Maximal Isometric Voluntary Contraction (MIVC). Children compared to adults have higher coactivation during plantar flexion $[17,18]$ and elbow flexion [13] but no difference is observed during knee extension [34] and during maximal isokinetic knee contractions [6].

The effect of joint angle has not been extensively studied in children. Marginson \& Eston [31] and Marginson et al. [32] reported that adults produced less relative knee extension torque(corrected to the maximum one) than children at flexed knee position higher than $80^{\circ},\left(0^{\circ}\right.$ is knee full extension $)$ due to the more compliant muscle tendon unit that children have [26, 28]. O'Brien et al. [34] however did not observed such differences between adults and children studying in the TJA relationship in a range of motion between 50 and 
90 deg. Besides, O'Brien et al., [34] reported that boys and adults did not have any difference, in the joint angle that maximal torque is produced and in the activity of the evaluated agonist and antagonist muscles across the joint. Nonetheless, according to our best knowledge there is no information about the differences in neuromuscular activity between children and adults at joint angles close to knee full extension or close to full flexion. This is an important issue if we consider that Anterior Cruiciate Ligament (ACL) loading occurs when knee is extended $[1,25]$ and that higher antagonist activity is expected at higher flexed position due to neural factors [27]. Furthermore, there is no information regarding the influence of joint angle in relative torque (corrected to body mass) if we consider that generally this is a conflicting issue. Depending on the applied normalisation method, in some cases equal values have been reported between age groups while in other, higher values for adults [47].

Based on the above, the purpose of this study was to investigate the differences in relative torque, agonist and antagonist activation between prepubertal boys and male adults and the effect of knee joint angle.

\section{MATERIAL AND METHODS}

\section{Subjects}

Twenty five prepubescent boys (age 9.8 \pm 1.1 years; height $144.1 \pm 7.2 \mathrm{~cm}$; body mass $40.7 \pm 9.0 \mathrm{~kg}$ ) and twenty five adult males (age $29.6 \pm 5.0$ years; height $181.0 \pm 5.3 \mathrm{~cm}$; body mass $83.5 \pm 8.6 \mathrm{~kg}$ ) volunteered to participate in this study. Parental and subject informed consent was taken prior to the participation in the experiment. Prior to the test all subjects passed medical examination. None of them was systematically trained or had any injury or neuromuscular disease at the lower limbs. All children were examined by a medical doctor who classified them to the first or second maturation stage according to Tanner's criteria [46]. The screening procedure excluded subjects having body fat more than $25 \%$ of their body mass because this could bias the EMG recordings. The study was performed according to the principles of the Ethics Committee of Aristotle University of Thessaloniki. 


\section{Instrumentation}

All MIVCs were performed on a Cybex Norm (Lumex Corporation, Ronkohoma, NY) dynamometer which was calibrated prior testing according to the procedures recommended by the manufacturer. The EMG recordings were captured with the Neuropack Four Mini device (Nihon Kohden Co.) which was connected with the Biopac, MP100 (Biopac Systems, Inc., Goleta). For anthropometric characteristics and body mass evaluation the following instruments were used: Height meter, Caliber for body fat mass.

\section{Procedure}

All subjects visited our laboratory two times, a week apart. The aim of the first visit was to inform and familiarize the participants with the dynamometry and testing procedures. During this session, subjects were at prone position and exerted submaximal and maximal knee flexions. Afterwards the subjects were familiarized at positions which responded to the $5 \%, 50 \%$, and $95 \%$ of their maximal range of knee maximal flexion (Table 1). The maximal knee flexion was evaluated energetically. Three trials were performed and the average values were finally accepted.

The MIVC was recorded for further evaluation during the second visit. The trunk, waist and thigh of the right leg of the subjects were stabilized at prone position with Velcro straps. The rotation axis of the dynamometer was aligned carefully with the approximate center of rotation of the knee on the posterior aspect of the lateral femoral condyle. From this position the subjects performed MIVC at 5\%, $50 \%, 95 \%$ of their maximal Range of Motion (MROM, $0^{\circ}$ defined as the position of full knee extension). The selection of fixed joint angles would respond to different stretching output for each subject and for this reason percentages of the ROM were selected. Besides according to Maganaris et al. [30] flexibility affects joint/torque relationship.

Before the MIVC evaluation the participants performed a specific warming up 15-20 submaximal isometric contractions with gradually increasing intensity. Then, they performed maximal isometric extension and flexion lasting $5 \mathrm{~s}$ each, with verbal encouragement and visual feedback of the torque output. A visual marker on the screen indicating their previous maximum assisted them to try achieving better performance. This procedure was continued until the last three trials showed no further increase in torque provided that all of three of them did not differ more than 5\% from each other. To avoid any 
fatigue effect the interval between maximal trials was 3 minutes. The highest value was selected as the subject's MIVC. The lean body mass was evaluated according to Slaughter at al. [41] and torque was normalized to their body (BM) and lean body mass.

\section{EMG recording}

The EMG activity was differentially recorded using bipolar surface electrodes $(\mathrm{Ag}-\mathrm{AgCl})$ of $0.8 \mathrm{~cm}$ diameter and the inter-electrode distance was set at $1.2 \mathrm{~cm}$. Before the electrode placement, the skin surface was shaved, abraded with sand paper and cleaned with alcohol wipes in order to reduce skin resistance below $5 \mathrm{k} \Omega$. Skin resistance was measured with the built-in device of the Neuropack apparatus. The surface of the electrodes were covered with a conduction gel (Ten20) and fixed with adhesive tape on the skin. The electrode cables were fixed with tape as well. The electrode placement sites were identified exerting a MIVC from the seated position for vastus medialis (VM) and vastus lateralis (VL) and from prone position for the biceps femoris (BF). The electrode location for the VM was the distal portion of the muscle, above and medially from the superior border of the patella in the one third of the distance between epicondyle and greater trochanter. The electrodes were also placed on the VL laterally to the rectus femoris, on the bulk of the muscle, half-way between the lateral femoral epicondyle and greater trochanter. For the $\mathrm{BF}$ the electrodes were located over the long head of BF, half way on the line between the ischial tuberosity and head of the fibula. The ground electrode was positioned on the bony surface on the lateral epicondyle.

Torque exerted at the $5 \%$ and $95 \%$ of maximal Range of Motion was normalised to torque exerted at $50 \%$ of ROM.

\section{Signal processing}

The EMG signal was amplified (x1000), $10 \mathrm{~Hz}$ to $500 \mathrm{~Hz}$ bandpass filtered. The analog signals of the dynamometer (torque and angular position) and EMG device were digitized at sampling rate of $1 \mathrm{kHz}$ through the integrated A/D 16bit card of the Biopac MP 100 Data Acquisition unit (Biopac Systems, Inc., Goleta, CA). The EMG signal was fully rectified, integrated and averaged (iaEMG). The iaEMG value of $\mathrm{VM}, \mathrm{VL}$, and $\mathrm{BF}$ was calculated $500 \mathrm{~ms}$ before and after the maximal torque. All data stored in a computer for further analysis by the Acknowledge software program (Biopac Systems Inc., CA). 
The antagonist EMG activity of BF was expressed as percentage of the BF EMG recorded during maximal voluntary isometric flexion.

\section{Statistical analysis}

Standard statistical methods were used for the calculation of mean values and standard deviations (SD). The dependent variables for torque, EMG and co-activation, were analyzed with $2 \times 3$ mixed repeated measures ANOVA with age (prepubescents, adults) and joint angle $(5 \%, 50 \%, 95 \%)$, as the independent variables. Post-hoc comparisons of the treatment means (Tukey's test) were used if appropriate. Interactions, main effects and mean differences were considered significant and reported as such when the level of probability reached or exceeded 0.05 .

\section{RESULTS}

The highest peak value was observed during MVC of knee extensors in $50 \%$ for both age groups. The two-way interaction effect was also significant on knee extensor moment. There was a significant F-ratio for the Joint Angle $\left(\mathrm{F}_{2.96}=200.8 ; \mathrm{p}<0.001\right)(50 \%>95 \%>5 \%)$ and Age $\left(\mathrm{F}_{1.48}=392.2 ; \mathrm{p}<0.001\right)$ (adult $>$ prepubescent males) (Figure 1; Table 1).

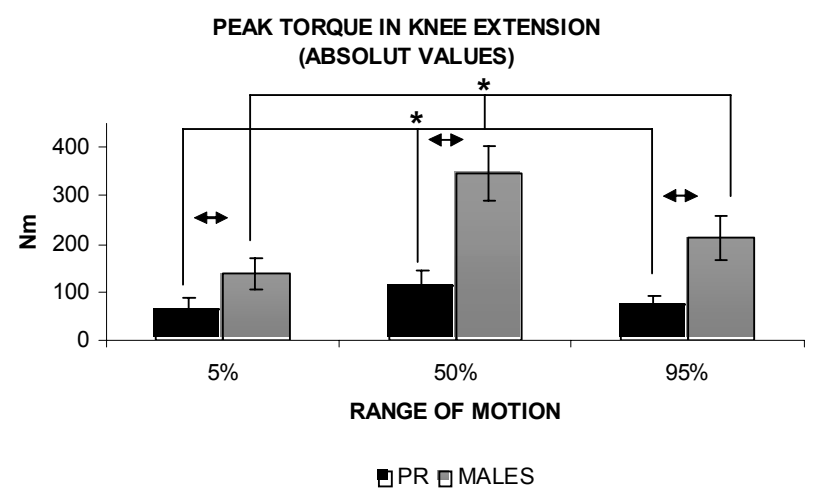

Figure 1. Peak torque values in knee extension (absolute values) of children and adults during MIVC. Horizontal arrows and asterisks indicate significant difference between the knee flexion angles and the age groups, respectively. 
Table 1: Maximal Range of Motion and 5\%, 50\% and 95\% of max ROM (in degrees) for the two age groups.

Mean (SD) values and post-hoc test comparison results of the factors Age and Angle for the knee extension torque in absolute and normalized values $(\mathrm{p}<0.05)$.

Mean (SD) values and post-hoc test comparison results of the factors Age and Angle for the EMG activity (in $\mathrm{mV}$ ) of $\mathrm{VM}, \mathrm{VL}$ and $\mathrm{BF}$ and antagonist activity of BF.

\begin{tabular}{|c|c|c|c|c|c|c|}
\hline & \multicolumn{3}{|c|}{ Prepubescent $(n=25)$} & \multicolumn{3}{|c|}{ Adults $(n=25)$} \\
\hline $\begin{array}{l}\text { Range of } \\
\text { Motion (ROM) } \\
\text { (deorees) }\end{array}$ & $5 \%$ & $50 \%$ & $95 \%$ & $5 \%$ & $50 \%$ & $95 \%$ \\
\hline & $\begin{array}{r}6.41 \\
(0.2) \\
\end{array}$ & $\begin{array}{c}61.6 \\
(11.8) \\
\end{array}$ & $\begin{array}{c}121.79 \\
(4.7)\end{array}$ & $\begin{array}{c}6.2 \\
(0.2) \\
\end{array}$ & $\begin{array}{c}60.4 \\
(11.2) \\
\end{array}$ & $\begin{array}{l}119.3 \\
(4.6) \\
\end{array}$ \\
\hline $\begin{array}{l}\text { Max ROM } \\
(100 \%)\end{array}$ & \multicolumn{3}{|c|}{$\begin{array}{l}128.2 \\
(4.9)\end{array}$} & \multicolumn{3}{|c|}{$\begin{array}{l}125.6 \\
(4.9)\end{array}$} \\
\hline Peak torque & $5 \%$ & $50 \%$ & $95 \%$ & $5 \%$ & $50 \%$ & $95 \%$ \\
\hline $\begin{array}{l}\text { Knee extension } \\
(\mathrm{N} \cdot \mathrm{m})\end{array}$ & $\begin{array}{c}62.5 \\
(25.7)\end{array}$ & $\begin{array}{c}112.4^{\mathrm{ab}} \\
(32.5)\end{array}$ & $\begin{array}{c}74.6 \\
(16.2)\end{array}$ & $\begin{array}{l}138.1^{\dagger} \\
(32.6)\end{array}$ & $\begin{array}{c}347.6^{\dagger \mathrm{ab}} \\
(57.4)\end{array}$ & $\begin{array}{c}211.2^{\dagger c} \\
(46.2)\end{array}$ \\
\hline $\begin{array}{l}\text { Knee extension } \\
\text { torque normali- } \\
\text { zed to body } \\
\text { mass }\left(\mathrm{N} \cdot \mathrm{m} \cdot \mathrm{kg}^{-1}\right)\end{array}$ & $\begin{array}{c}1.5 \\
(0.5)\end{array}$ & $\begin{array}{l}2.8^{a b} \\
(0.7)\end{array}$ & $\begin{array}{c}1.9 \\
(0.5)\end{array}$ & $\begin{array}{c}1.7 \\
(0.4)\end{array}$ & $\begin{array}{c}4.2^{\dagger a b} \\
(0.6)\end{array}$ & $\begin{array}{l}2.5^{\dagger c} \\
(0.5)\end{array}$ \\
\hline $\begin{array}{l}\text { EMG of VM } \\
\text { extension } \\
(\mathrm{mV})\end{array}$ & $\begin{array}{l}1.7 \\
(0.7)\end{array}$ & $\begin{array}{c}1.6 \\
(0.6)\end{array}$ & $\begin{array}{l}1.5 \\
(0.7)\end{array}$ & $\begin{array}{l}2.3^{\dagger} \\
(0.8)\end{array}$ & $\begin{array}{l}2.3^{\dagger} \\
(0.9)\end{array}$ & $\begin{array}{l}2.1^{\dagger} \\
(1.0)\end{array}$ \\
\hline $\begin{array}{l}\text { EMG of VL } \\
\text { extension } \\
(\mathrm{mV})\end{array}$ & $\begin{array}{c}1.7 \\
(0.6)\end{array}$ & $\begin{array}{l}1.6 \\
(0.7)\end{array}$ & $\begin{array}{c}1.5 \\
(0.7)\end{array}$ & $\begin{array}{l}2.9^{\dagger} \\
(1.1)\end{array}$ & $\begin{array}{l}2.8^{\dagger \mathrm{b}} \\
(1.0)\end{array}$ & $\begin{array}{l}2.3^{\dagger \mathrm{c}} \\
(1.1)\end{array}$ \\
\hline $\begin{array}{l}\text { EMG of BF } \\
\text { flexion } \\
(\mathrm{mV})\end{array}$ & $\begin{array}{l}1.9 \\
(0.7)\end{array}$ & $\begin{array}{l}1.7^{\mathrm{b}} \\
(0.6)\end{array}$ & $\begin{array}{l}1.1^{\mathrm{c}} \\
(0.6)\end{array}$ & $\begin{array}{l}3.0^{\dagger} \\
(1.3)\end{array}$ & $\begin{array}{c}2.3^{\dagger a b} \\
(0.9)\end{array}$ & $\begin{array}{l}1.4^{\mathrm{c}} \\
(0.6)\end{array}$ \\
\hline $\begin{array}{l}\text { Co-activation } \\
\text { BF }\end{array}$ & $\begin{array}{c}32.8 \\
(11.0) \\
\end{array}$ & $\begin{array}{l}27.6^{\mathrm{ab}} \\
(11.0)\end{array}$ & $\begin{array}{c}38.1 \\
(12.5)\end{array}$ & $\begin{array}{c}23.6^{\dagger} \\
(13.4)\end{array}$ & $\begin{array}{c}20.6^{\dagger a b} \\
(9.1)\end{array}$ & $\begin{array}{c}35.3^{\dagger} \\
(10.8)\end{array}$ \\
\hline
\end{tabular}

${ }^{\dagger}$ significant difference between the groups

${ }^{a}$ significant difference between the 5\% and 50\% ROM

${ }^{\mathrm{b}}$ significant difference between the $50 \%$ and $95 \%$ ROM

${ }^{\mathrm{c}}$ significant difference between the $5 \%$ and $95 \%$ ROM 
When torque was normalized to body mass (BM), adult males had greater values than prepubescent, $(\mathrm{p}<0.05)$. Between groups data are presented in Figure 2.

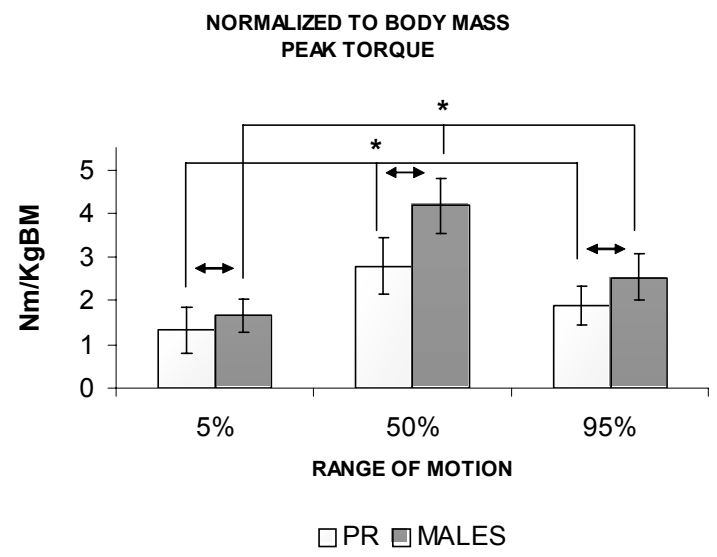

Figure 2. Peak torque values in knee extension (normalized to body mass) of children and adults during MIVC. Horizontal arrows indicate significant difference between the knee flexion angles.

Normalizing the torque to the respective values during the contraction at the midpoint of ROM (50\%), data showed significant effects for the factor Age during extension $\left(\mathrm{F}_{1.48}=13.2 ; \mathrm{p}<0.001\right)$.

The iaEMG of the VM and VL was similar at all angles for both age groups (Figure 3). For the antagonist normalized EMG of BF there was a significant F-ratio for Age $\left(\mathrm{F}_{1.48}=9.0 ; \mathrm{p}<0.05\right)$ and Joint Angle $\left(\mathrm{F}_{2.96}=111.6 ; \mathrm{p}<0.01\right)$ (Figure 4). Post-hoc Tukey's test indicated that the antagonist EMG recorded at 5\% and $95 \%$ of ROM was significantly higher compared to the EMG recorded at the midpoint joint position for both groups (Figure 4: Table 1). 
IAEM G OF KNEE EXTENSORS

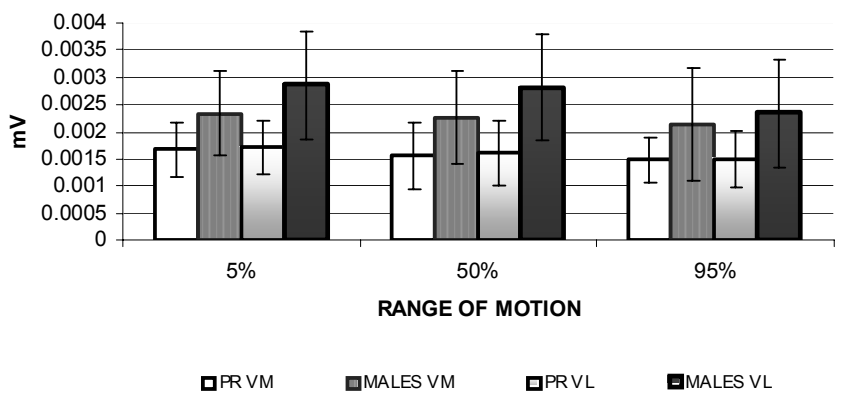

Figure 3. Agonist EMG activity of children and adults during MIVC for the vastus medialis (VM) and vastus lateralis (VL) during knee extension. Horizontal arrows and asterisks indicate significant difference between the knee flexion angles and the age groups, respectively.

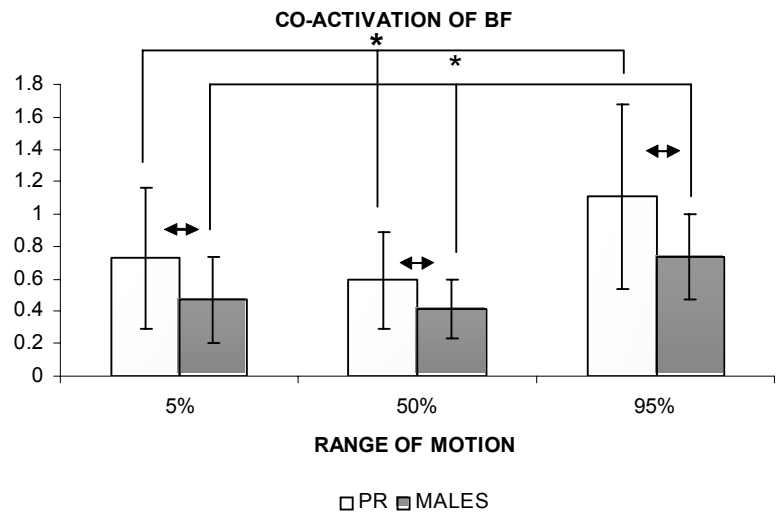

Figure 4. Antagonistic EMG activity of the biceps femoris (BF) during maximal knee flexion at different knee angles. The antagonistic EMG is normalized to the maximum EMG recorded when the respective muscle was acting as agonist at the respective knee joint angle. Horizontal arrows and asterisks indicate significant difference between the knee flexion angles and the age groups, respectively. 


\section{DISCUSSION}

The main findings of the current study were that the absolute and relative torque was higher in adult males for all selected joint angles while when the torque was normalized to the torque exerted at $50 \%$ of MROM statistical differences were observed only at the $5 \%$ position. Agonist activity remained constant both in prepubescent boys and adult males irrespectively of the selected joint angles. Coactivation was higher in the two extreme angles in both age groups while prepubescent boys exerted higher values relatively to the adult men.

The obtained absolute torque was higher in adults compared to prepubescents in all tested angles as expected. When the torque at 5\% and $95 \%$ of the ROM was normalized to the exerted torque at the midpoint position, significant differences between the age groups were observed only at the $5 \%$ position. The absence of significant differences at the position of $95 \%$ of ROM despite the higher decrease in adults could be supported by Marginson \& Eston [31] and Marginson et al. [32] who showed that the relative torque decreased significantly more in adults than in children after 90 degrees of knee flexion.

Regarding the effect of joint angle our results showed that relative torque was higher in adults in all selected joint angles. Generally speaking the differences in relative torque output between adults and children is a conflicting point. Some researchers reported that torque differences between different age groups were eliminated when absolute strength measures were normalized to body parameters [35, $40]$. On the contrary, it has also been reported that differences between ages still remained even after strength normalization $[6,13,19,20]$. According to Tonson et al. [47] in some cases it depends on the applied normalization method, since relative force was higher in adults when torque was normalized to Anatomical Cross Sectional Areas (ACSA) and muscle volume as derived from anthropometric parameters. However, normalized torque was not different between age groups when it was expressed in respect to muscle volume as estimated by MRI. Taking into account the above we may comment the following. Firstly, Tonson et al. [47] comments might be valid only for the handgrip contraction if we consider that the same methods for relative torque evaluation give different result across different muscles and between different genders [13, 20]. Secondly, the more valid predictor for torque output is the ACSA and not the muscle 
volume [5]. The latter is more valid for power normalization [5]. The above mentioned studies at previous works which normalized the absolute torque to the ACSA and reported higher values for adults compared to children $[13,20]$ support indirectly our findings.

The differences in relative torque between the age groups could be explained by potential differences in the extent of motor unit activation. However, it seems that this is not the case, since prepubertal boys and adults activate their knee extensor motor units in the same extent $[34,44]$. Other arguments for causing the higher relative torque in adults are the differences in the moment arm which is lower in children [34] and the antagonist muscle activity, which, according to our results, is higher in children and this counteracts the agonist muscle activation which is not differentiated between prepubescent boys and adult men. Therefore, the moment arm and the antagonist activity differences between the selected age groups can explain the lower relative torque in children.

The relevant studies related to the antagonist activity in different joint angles are conflicting. In some cases no effect of joint angle is reported $[4,8,16,34]$ while in other cases a higher coactivation exists at the extreme knee ankle [12, 23, 25, 27, 43] and ankle [30] joint angles. Concerning the knee joint it was reported that the higher coactivation at shorter muscle length (near full extension), could be attributed the synergy of Anterior Crusiate Ligament (ACL) with BF muscle at these joint angles due to the strain on ACL increased [13, 23, 43]. Another reason is that higher knee joint instability occurs when quadriceps muscle contracts at this position both in isometric [25] and concentric [1] conditions. In the case of increased coactivation at longer muscle length, it has been argued that joint afferents involvement might be involved [26] nonetheless, there is no concrete explanation. Therefore this issue needs further investigation. Besides our result indicate that both children and adults have common strategy for antagonist activity at least for the selected task.

We found also, that antagonist activity was higher in all selected joint angles in children. Previous comparisons of children with adults in antagonist activity lead to conflicting results. Specifically, in some cases a higher antagonist activity in children was observed for complex movements [15]. Co-contraction in three age groups of children during treadmill locomotion whereas in other cases during plantar flexion [17, 18] and elbow flexion [13] MIVC co-contraction was higher in children. However, a similar study for the knee 
extensors MIVC revealed no difference between age groups [34]. Regarding the effect of joint angle on antagonist activity in children and adults for the knee extensors, only one study [34] reported no differences in coactivation between age groups for a ROM between 50 and 90 degrees. This controversy to our results could be attributed to methodological differences for the evaluation of the antagonist activation. In the study of O'Brien et al. [34] the torque output of the antagonist muscles is estimated, as derived from the antagonist EMG activity, whereas in our study, the coactivation calculation remains strict to the EMG values of the antagonist muscle (normalized to the EMG activity of the same muscle when acting maximally as agonist). Furthermore the examined ROM is different between the two studies. The present study evaluated more extreme positions. Last but not least, the leg extension in our experiment was executed from prone and not seated position. This difference may influence the muscle length of the quadriceps and especially the rectus femoris, and consequently this may influence the activation level [37]. Besides, keeping in mind that antagonist activity is task depended [22] the task selected in our study is very unusual in everyday life and therefore children may have been less experienced in such tasks (learning factor). Furthermore, knee joint laxity is higher in children compared to adults [2] and this may results in a higher co-contraction as a protective mechanism.

Concerning the agonist EMG activity our findings indicate fairly constant values between the groups and between the angles. However, the existing literature relevant to adults shows some controversy in this issue. Specifically, it was reported that activity in men is higher at shorter muscle lengths $[4,25,29]$ because the neuronal transmission is lower than in the other joint angles [24] and consequently, the central motor drive increases compensatory, by an increase in the frequency domain. There are also studies which report that men have higher activation at the angle in which higher torque is produced, based on the fact that higher recruitment occurs due to the higher level of the exerted torque. For the case where higher muscle activation was observed at the longer muscle length $[45,48]$ the basic explanation was the higher enhancement of muscle spindle activity [7]. However, in other cases agonist activity was kept constant throughout joint angles [10, 33, 48]. A possible explanation could be given based on the observations of Brondino et al. [11] who reported that muscle inhibition -possibly caused by Golgi tendon organ- was constant 
throughout all tested joint angles. However, other factors which can explain the observed conflicts regarding muscle activation relative to joint angles, are the artifacts which were observed in EMG recording at different joint angles due to shift of muscle during contraction, [14] or the signal cancellation which occurs during surface EMG evaluations [21].

One limitation of this study was that only three different joint angles were evaluated. Possibly it could be useful in future studies to use more joint angles for evaluation.

These findings suggest that the joint angles caused a deficit in neuromuscular performance of children and it could be attributed to their higher antagonist activity.

\section{REFERENCES}

1. Aagaard P., Simonsen E. B., Andersen J. L., Magnusson S. P., Bojsen-Moller F., Dyhre-Poulsen P. (2000) Antagonist muscle coactivation during isokinetic knee extension. Scand. J. Med. Sci. Sports 10: $58-67$

2. Ahmad C.S., Clark A. M., Heilmann N., Schoeb J. S., Gardner T. R., Levine W.N. (2006) Effect of gender and maturity on quadriceps-to hamstring strength ratio and ACL laxity. Am. J. Sports Med. 34: 370374

3. Asai H., Aoki J. (1996) Force development of dynamic and static contractions in children and adults. Int. J.Sports Med. 17: 170-174

4. Babault N., Pousson M., Michaut A., Van Hoecke J. (2003) Effect of quadriceps femoris muscle length on neural activation during isometric and concentric contractions. J. Appl. Physiol. 94: 983-990

5. Bamman M. M., Newcomer B. R., Larson-Meyer D. E., Weinsier R. L., Hunter G. R. (2000) Evaluation of the strength-size relationship in vivo uses various muscle size indices. Med. Sci. Sports Exerc. 32: $1307-1313$

6. Bassa E., Patikas D., Kotzamanidis C. (2005) Activation of antagonist knee muscles during isokinetic efforts in prepubertal and adult males. Ped. Exerc. Sci. 17: 65-75

7. Becker R. Awizsus F. (2000) Physiological alterations of maximal voluntary quadriceps activation by changes of knee joint angle. Muscle Nerve 24: 667-672 
8. Beltman J. G., Sargeant A. J., Ball D., Maganaris C. N., de Haan A. (2003) Effect of antagonist muscle fatigue on knee extension torque. Pflugers Arch. 446: 735-741

9. Blimkie C. J. R. (1989) Age-and sex-associated variation in strength during childhood: anthropometric, morphologic, neurologic and biomechanical correlates. In. Perspective in Exercise Science and Sports Medicine vol. 2 Youth, Exercise and Sport, C. V. Gisolfi, D. R. Lamb (Eds), Benchmark Press, Indianapolis. 99-163

10. Bobbert M. F. Harlaar J. Q. (1992) Evaluation of moment-angle curves in isokinetic knee extension. Med. Sci. Sports Exerc. 25: 251259

11. Brondino L., Suter E., Lee H-D., Herzog W. (2002) Elbow flexor inhibition as a function of muscle length. J. Appl. Biomech. 18: 4656

12. Draganich L. F., Jaeger R. J., Krali A. R. (1989) Coactivation of the hamstrings and quadriceps during extension of the knee. J. Bone Joint Surg. Am. 71: 1075-1081

13. Falk B., Usselman C,. Dotan R., Brunton L., Klentrou P., Shaw J., Gabriel D. (2009) Child-adult differences in muscle strength and activation pattern during isometric elbow flexion and extension. Appl. Physiol. Nutr. Metab. 34: 609-615

14. Farina D., Merletti R., Enoka M. (2004) The extraction of neural strategies from the surface EMG. J. Appl. Physiol. 96: 1486-1495

15. Frost G. J., Dowling K., Dyson K., Bar-Or O. (1997) Cocontraction in three age groups of children during treadmill locomotion. J. Electromyogr. Kinesiol. 7: 179-186

16. Grabiner M. D., Koh T. J., Miller G. F. (1992) Further evidence against a direct automatic neuromotor link between the ACL and hamstrings. Med. Sci. Sports Exerc. 24: 1075-1079

17. Grosset J., Mora I., Lambertz D., Perot C. (2006) Voluntary activation of the triceps surae in prepubertal children. J. Electromyogr. Kinesiol. 18: 455-465

18. Hatzikotoulas K., Patikas D., Bassa E., Paraschos I., Kotzamanidis C. (2007) Differences in voluntary activation between adult and prepubertal males. In: Children and exercise XXIV: The Proceedings of the 24th Pediatric Work Physiology Meeting, T. Jürimäe, N. Amstrong, J. Jürimäe (Eds). Oxon: Routledge. 247-251

19. Kanehisa H., Ikegawa S., Tsunoda N., Fukunaga T. (1994) Strength and cross-sectional area of knee extensor muscles in children. Eur. J. Appl. Physiol. 68: 402-405 
20. Kanehisa H., Yata H., Ikegawa S., Fukunaga T. (1995) A crosssectional study of the size and strength of the lower leg muscles during growth. Eur. J. Appl. Physiol. 72: 150-156

21. Keenan K .G., Farina D., Maluf K. S., Merletti R., Enoka R. M. (2005) Influence of amplitude cancellation on the simulated surface electromyogram. J. Appl. Physiol. 98: 120-131

22. Kellis E. (1998) Quantification of quadriceps and hamstring antagonist activity. Sports Med. 25: 37-62

23. Kellis E., Baltzopoulos V. (1996) Agonist and antagonist moment and EMG-angle relationship during isokinetic eccentric and concentric exercise. Isokinet. Exerc.Sci. 6: 79-87

24. Kennedy P., Cresswell A. (2001) The effect of muscle length on motor-unit recruitment during isometric plantar flexion in humans. Exp. Brain Res. 137: 58-64

25. Kingma I., Aalbersberg S., Van Dieen J. H. (2004) Are hamstrings activated to counteract shear forces during isometric knee extension efforts in healthy subjects? J. Electromyogr. Kinesiol. 14: 307-315

26. Kubo K., Kanehisa H., Fukunaga T. (2003) Gender differences in the viscoelastic properties of tendon structures. Eur. J. Appl. Physiol. 88: $520-526$

27. Kubo K., Tsunoda N., Kanehisa H., Fukunaga T. (2004) Activation of agonist and antagonist muscles at different joint angles during maximal isometric efforts. Eur. J. Appl. Physiol. 91: 349-352

28. Lambertz D., Mora I., Grosset J., Perot C. (2003) Evaluation of musculotendinous stiffness in prepubertal children and adults, taking into account muscle activity. J. Appl. Physiol. 95: 64-72

29. Maffiuletti N., Lepers R. (2003) Quadriceps femoris torque and EMG activity in seated versus supine position. Med. Sci. Sports Exerc. 35:1511-1516

30. Maganaris, C., Baltzopoulos V., Sargeant A., (1998). Differences in human antagonistic ankle dorsiflexor coactivation between legs; can they explain the moment deficit in the weaker plantarflexor leg? Exp. Physiol. 83: 843-855

31. Marginson V., Eston R. (2001) The relationship between torque and joint angle during knee extension in boys and men. J. Sports Sci. 19: 875-880

32. Marginson V., Rowlands A. V., Gleeson N. P., Eston R. G. (2005) Comparison of the symptoms of exercise-induced muscle damage after an initial and repeated bout of plyometric exercise in men and boys. J. Appl. Physiol. 99: 1174-1181 
33. Newman S. A., Jones G., Newham D. J. (2003) Quadriceps voluntary activation at different joint angles measured by two stimulation techniques. Eur. J. Appl. Physiol. 89: 496-499

34. O’Brien T. D., Reeves N. D., Baltzopoulos V., Jones D. A., Maganaris C. N. (2009) Moment arms of the knee extensor mechanism in children and adults. J. Anat. 215: 198-205

35. Pääsuke M., Ereline J., Gapeyeva H. (2000) Twitch contraction properties of plantar flexor muscles in pre- and post-pubertal boys and men. Eur. J. Appl. Physiol. 82: 459-464

36. Rassier D., MacIntosh R., Herzog W. (1999) Length depedence of active force production in skeletal muscle. J. Appl. Physiol. 86: $1445-1457$

37. Rochette L., Hunter S. K., Place N., Lepers R. (2003) Activation varies among the knee extensor muscles during a submaximal fatiguing contraction in the seated and supine postures. J. Appl. Physiol. 95: $1515-1522$

38. Round J. M., Jones D. A., Honour J. W., Nevill A.M., (1999) Hormonal factors in the development of differences in strength between boys and girls during adolescence: a longitudinal study. Ann. Hum. Biol. 26: 49-62

39. Seger J. Y., Thorstensson A. (1994) Muscle strength and myoelectric activity in prepubertal and adult males and females. Eur. J. Appl. Physiol. 69: 81-87

40. Seger J. Y., Thorstensson A. (2000) Muscle strength and electromyogram in boys and girls followed through puberty. Eur. J. Appl. Physiol. 81: 54-61

41. Slaughter M. H., Lohman T. G., Boileau R. A., Horswill C. A., Stillman R. J., Van Loan M. D., Bemben D. A. (1988) Skinfold equations for estimation of body fatness in children and youth. Hum. Biol. 60: 709-723

42. Smits-Engelsman B. C. M., Westenberg Y., Duysens J. (2003) Development of isometric force and force control in children. Cogn. Brain Res. 17: 68-74

43. Solomonow M., Baratta R., Zhou B., Shoji H., Bose W., Beck C., D' Ambrosia R. D. (1987) The synergetic action of the ACL and thigh muscles in maintaining joint stability. Am. J. Sports Med. 15: 207213

44. Streckis V., Skurvydas A., Ratkevicius A. (2007) Children are more susceptible to central fatigue than adults. Muscle Nerve 36: 357-363

45. Suter E., Herzog W. (1997) Extent of muscle inhibition as a function of knee angle. J. Electromyogr. Kinesiol. 7: 123-130 
46. Tanner J. (1962) Growth and adolescence, $2^{\text {nd }}$ edn., Blackwell, Oxford.

47. Tonson A., Ratel S., Fur Y., Cozone P., Pendahan D. (2008) Effect of maturation on the relationship between muscle size and force production. Med. Sci. Sports Exerc. 40: 918-925

48. Zabik R. M., Dawson M. L. (1996) Comparison of force and peak EMG during a maximal voluntary isometric contraction at selected angles in the range of motion for knee extension. Percept. Mot. Skills 83: 976-978

\section{Correspondence to:}

Christos Kotzamanidis

Department of Physical Education and Sports Sciences, Aristotle University of Thessaloniki, Thessaloniki 54006, Greece

E-mail: kotzaman@phed.auth.gr 